\title{
Cuidados de enfermería a un paciente con intento autolítico por metanol
}

\author{
$M^{\text {a }}$ Sol Martínez Barquinero- Marta Ocaña Carreño
}

Servicio de Nefrología. Unidad de Dialisis. Hospital Universitario de Guadalajara

\section{Introducción}

Hasta hace unos años los cuidados autolíticos provocados por sustancias como el metanol eran poco frecuentes. En la actualidad la problemática psicosocial ha cambiado, y esto hace que tengamos que tratar ocasionalmente a estos pacientes.

El diagnóstico y tratamiento médico, unidos a una adecuada actuación de enfermería es imprescindible para intentar restablecer la situación crítica del paciente. EI papel de enfermería es fundamental para tratar a estos pacientes, con especial relevancia en los cuidados clínicos y la utilización de hemodiálisis prolongada y hemodiafiltración (HDFVVC) para resolver la intoxicación aguda.

Nuestro objetivo fue evaluar los cuidados de enfermería y de las técnicas de depuración extrarrenal (hemodiálisis prolongada y hemodiafiltración continua) en la intoxicación aguda por metanol que se realizaron a un paciente de cuarenta años de edad, que acudió a nuestro hospital. Para ello se realizó una revisión retrospectiva del historial clínico, junto con gráfica y parámetros de la Hemodiálisis y de los registro de parámetros bioquímicos y de laboratorio de interés

\section{Evolución}

A su llegada al Servicio de Urgencias presentaba: cefalea, sensación de mareo, irritabilidad y lenguaje incoherente,

\begin{tabular}{|c|}
\hline Correspondencia: \\
$M^{\text {a }}$ Sol Martínez Barquinero \\
Unidad de Diálisis \\
Hospital Universitario de Guadalajara \\
C/ Donantes de Sangre s/n \\
19002 Guadalajara \\
msmartinez@sescam.org \\
\hline
\end{tabular}

sufriendo deterioro progresivo, por lo que fue ingresado en UCI donde se evidenció una acidosis metabólica severa con deterioro de la función renal. Ante la sospecha de intoxicación aguda por metanol se indicó tratamiento con hemodiálisis prolongada, llevándose a cabo una hemodiálisis de siete horas de duración con una membrana de polisulfona de alta permeabilidad de $2,1 \mathrm{~m}^{2}$ de superficie y flujo de sangre de $300 \mathrm{ml} / \mathrm{min}$.

Posteriormente fue tratado con hemodiafiltración continua con membrana de poliacrilonitrilo, flujo de $200 \mathrm{ml} / \mathrm{min}$, baño de bicarbonato sódico al que se le añadió etanol (1litro/hora) y reposición post-dilucional (1litro/hora), con Hemosol ${ }^{\circledR}$. Se registraron las modificaciones analíticas del paciente a lo largo de la sesión de la hemodiálisis. Los niveles de metanol antes de la hemodiálisis fueron de $1793 \mathrm{mg} / \mathrm{l}$ y después de la sesión prolongada de 173,4 $\mathrm{mg} / \mathrm{dl}$. El tratamiento con hemodiálisis y posteriormente con la hemodiafiltración continua mejoraron la acidosis metabólica y el deterioro de la función renal del paciente. No obstante, el paciente presentó inestabilidad hemodinámica importante, con empeoramiento de su situación neurológica. En el TAC se objetivo una herniación trastentorial que no respondió al tratamiento. Ante el diagnóstico de muerte cerebral, se solicitó autorización para donación de órganos, siendo aceptada por sus familiares, realizándose una extracción multiorgánica.

\section{Discusión}

La intoxicación aguda por metanol es una situación grave que requiere un tratamiento coordinado y urgente. EI papel de enfermería de hemodiálisis es fundamental, ya que la mortalidad en pacientes no tratados o tratados tardíamente es muy elevada. Se deben instaurar técnicas de tratamiento sustitutivo de modo precoz ante la sospecha del proceso, aunque no se disponga de niveles de metanol en sangre.

La mortalidad de estos pacientes, está relacionada sobre todo con el retraso en acudir a un centro sanitario, niveles 
elevados de metanol en plasma, $\mathrm{pH}$ sanguíneo menor de 7 y situación de coma al ingreso.

La pronta instauración de la técnica de hemodiálisis, con membranas de alta permeabilidad, a altos flujos, con periodos de tratamiento prolongados y con una adecuada actuación de enfermería, rápida y eficaz, es fundamental para intentar salvar la vida del paciente 0 , como en el caso que referimos, mantener la estabilidad hemodinámica y hacer la posible la donación.

\section{Bibliografía}

1. Brent J, McMartin K, Phillips S, et al. Fomepizole for the treatment of methanol poisoning. $\mathrm{N}$ Engl J Med $2001 ; 344$ (6):424-9.
2. Ghosh A, Boyd R. Leucovirin (calcium folinate) in "antifreeze" poisoning. Emerg Med J 2003; 20(5):466.

3. Mora-Ordóñez JM, Martín D, Curiel Balsera E, Muñoz Bono J. Intoxicación mortal por metanol: donante de órganos. Med Clin 2008; 130 (1):37-9.

4. Santana L, García Cantón C, Martínez Cuéllar S, Sánchez Palacios M. Intoxicación grave por metanol y tolueno: a propósito de un caso. Nefrología 2007; 27(4):517-8.

5. Youssef GM, Hirsch DJ. Validation of a method to predict required dialysis time for cases of methanol and ethylene glycol poisoning. Am J Kidney Dis 2005; 46(3):509-511. 